DOI: https://doi.org/10.15407/techned2022.01.003

\title{
VIRIAL THEOREM LIMITATIONS FOR THE TOROIDAL MAGNETIC ENERGY STORAGE CFUSED BY THE LOCATION OF SUPPORT STRUCTURE ELEMENTS AND THEIR MECHANICAL PROPERTIES
}

\author{
Yu.M. Vasetsky ${ }^{*}$ \\ Institute of Electrodynamics National Academy of Sciences of Ukraine, \\ pr. Peremohy, 56, Kyiv, 03057, Ukraine. \\ E-mail: $\quad$ yuriy.vasetsky@gmail.com
}

Based on the virial theorem, the influence of the following factors to characteristics of mechanical support systems of toroidal magnetic energy storage is considered: the configuration of the coils, the support system elements location under compressive forces, the mechanical properties of the material, the distribution of the cross-sectional areas of the support rings and the corresponding distribution of radial forces. It is established that the volume of structure requirement depends only on the radii from which the coils transmit forces to the support rings. The found general relation, in contrast to the existing ones, establishes a relationship between all the parameters that determine the volume of the support structures. The characteristics of support systems are analyzed both for identical mechanical stresses and for identical mechanical properties of all support elements. The characteristics for specific examples of toroidal systems with circular coils are found. It is shown that systems with support elements in compression located on the side of the vertical axis of the torus have a significantly smaller volume of structure compared to other locations. The influence of the relative radial size of the torus cross-section and the distribution of the cross-sectional areas of the support rings on the structure requirement is analyzed. The relationship between dimensionless characteristics that determine the volume of elements subjected to mechanical stresses of compression and tension is noted. References 37, figures 8 , table 1 .

Key words: toroidal magnetic energy storage, virial theorem, structure under compression, support structure volume.

Introduction. The success of the use of superconducting magnetic energy storage (SMES) in largescale fusion installations [1 - 3] leads to interest in their widespread use in various technical fields. The advantage of the SMES compared to many other energy storage devices is related to the response speed to perturbations [4]. However, the high cost of installations limits their widespread use in improving the quality of electricity [5]. Reducing the cost, in particular, of its component associated with the support structures that are affected by electrodynamic forces, is an urgent task.

SMES as a fast-acting means of regulated consumer/source of energy in electric power systems can perform, in particular, the following functions: voltage and frequency stabilization [6 - 8]; increasing the level of static and dynamic stability, as well as the survivability of power systems [9 - 12]; damping of electromechanical oscillations and compensate the random oscillations of generation and power transmission [13 - 15]; in smart grid systems and in systems with renewable energy sources to compensate for power fluctuations [16 - 18]. The variety of tasks that can perform SMES, determines the appropriate choice, or special development of the superconducting storage, which primarily relates to the geometric configuration of its windings.

The value of the magnetic field energy stored in SMES for use in the power industry is in a fairly wide range $W=30 \div 10^{4} \mathrm{MJ}$. The maximum value is about an order of magnitude smaller than the value of the stored energy of the largest to date under construction thermonuclear installation ITER $\mathrm{W} \sim 10^{5}$ MJ. For SMES with a large accumulated magnetic field energy $W>10^{3}-10^{4} \mathrm{MJ}$, the mass of the supporting structures makes a significant contribution to the total number of materials of the magnetic system in addition to the superconducting winding [19].

(C) Vasetsky Yu.M., 2022

*ORCID ID: https://orcid.org/0000-0002-4738-9872 
There are several ways to reduce the total structural mass in toroidal energy storage. Reducing the structural mass due to the redistribution of electrodynamic forces, but with the complication of the geometry of the magnetic system and increasing stray fields [20], is achieved in helical toroidal windings [21 - 23], as well as using toroidal systems with tilted coils of special configuration [24 - 26] ]. In toroidal systems with flat coils without tilt, it is also possible to reduce the mass of the suppot system by choosing configurations with constant stresses in the structural elements. These are toroidal systems with D-shaped coils [27 - 29], which were studied primarily in the field of fusion, and devices with structural elements inside the toroidal volume, which can be used for electric power applications [30, 31].

The volume (mass) of structures has limitations that set the lower limit of the required volume (mass). General relations for the total structural masses of magnetic systems are formulated on the basis of the Clausius virtual theorem [32] and written by Levy for electromagnetic systems [33]. According to the theorem, the volume $V$ and, accordingly, the mass $M=\rho V$ with the density $\rho$ of unidirectionally stressed structure satisfy the condition:

$$
M=\rho V \geq \frac{\rho W}{<\sigma>},
$$

where $\langle\sigma\rangle$ is average stress.

If the part of the structure under tension $V_{t}$ is balanced by the structure under compression $V_{c}$, then

$$
V_{t}-V_{c} \geq \frac{W}{<\sigma>} \text {. }
$$

Volume $V_{c}$ can also be zero. An example of magnetic systems for which the compressive forces in the supporting systems may be zero are helical toroidal systems or systems with tilted coils. For this case, the total volume:

$$
V=V_{t}+V_{c} \geq 2 V_{c}+\frac{W}{<\sigma>}
$$

is determined by only volume $V_{t}$ under tension.

In magnetic energy storage, part of the elements is in compression, and the other part is subjected to tensile forces. In [32], for such systems, the corresponding volumes of stressed structures are presented as:

$$
V_{t}=\frac{W}{<\sigma_{t}>} Q_{t}, \quad V_{c}=\frac{W}{<\sigma_{c}>} Q_{c},
$$

where dimensionless characteristics $Q_{t}$ and $Q_{t}$ are determined by dimensionless parameters that characterize the configuration of the magnetic system. Here value $Q_{t}$ for structures under tension is positive and value $Q_{c}$ is negative in compression one. This definition of the sign of the characteristics corresponds to the positive values of tensile stresses and negative values of compressive stresses.

From the general statement valid for any configuration, current distribution and energy parts of poloidal and toroidal fields,

$$
\left|Q_{t}\right|+\left|Q_{c}\right| \geq 1
$$

it follows that the minimum value of the structure requirement is reached when

$$
Q_{t}=-Q_{c}+1 \text {. }
$$

For magnetic systems that have been built or designed, the minimum values were not achieved. The values resulting from the virtual theorem and the corresponding values in the designed and implemented magnetic systems can differ significantly [34]. However, the virtual theorem indicates a value that can be approached and indicates the lower limit of the structure requirement, less than which can not be achieved. Currently, based on the virial theorem, the structural limitations are compared both superconducting magnetic energy storage (SMES) and other types of energy storage [35]. These circumstances determine the relevance of research based on the general conditions of the theorem.

Expressions for the characteristics $Q_{t}$ and $Q_{c}$ found in [32] under certain assumptions and are valid in some cases of the support system. They not taking into account the location of the support elements and the mechanical properties of the structures material. Since the volumes of structures under compression and 
tension are directly related by relation (6), consideration of only one component gives an answer to the value of total structure requirement. So, the purpose of this work is to find for toroidal magnetic storage, based on the general statements, the characteristics of support systems which are subject to compression forces, and to study the influence of geometric configuration of toroidal magnetic field coils, the location of elements of support structure, mechanical material properties.

\section{Mathematic model. Basic relation for the support system.}

We assume that the winding consists of a large number of coils. In this case, the winding can be represented as a current surface of an infinite number of current filaments (Fig. 1). The toroidal configuration is characterized by a large radius of the torus, which is defined as average value between the smallest $\rho_{1}$ and the largest $\rho_{2}$ radii of the toroidal surface $R=\left(\rho_{2}+\rho_{1}\right) / 2$. The geometry of the torus cross-section will be

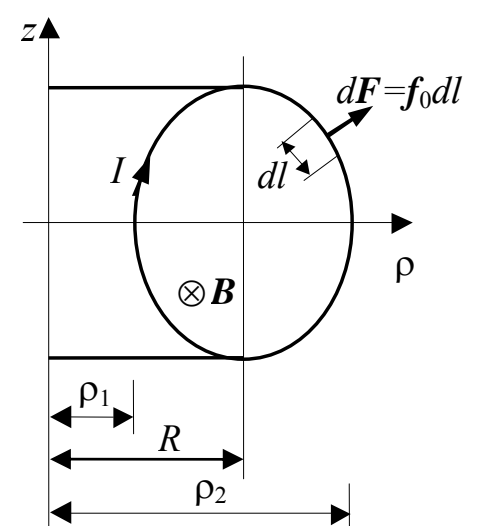

Fig. 1

each coil is characterized by dimensionless parameters $\varepsilon_{1}, \varepsilon_{i}$, where the first parameter determines the relative radial size of the cross-section torus $\varepsilon_{1}=\varepsilon=r / R=\left(\rho_{2}-\rho_{1}\right) / 2 R$, and other dimensionless parameters determine the shape of the torus cross-section and do not depend on the large radius $\varepsilon_{i}=r_{i} / r$.

The magnetic field $\boldsymbol{B}$ created by the current $I=I_{0} N$ of all coils $N$ is concentrated only inside the torus and is directed in the azimuthal direction along a single vector $\boldsymbol{e}_{\varphi}$ :

$$
\boldsymbol{B}=\frac{\mu_{0} I_{0} N}{2 \pi \rho} \boldsymbol{e}_{\varphi} .
$$

The linear density of electrodynamic forces acting to the current of

$$
\boldsymbol{f}_{0}=\frac{1}{2} I_{0} B \boldsymbol{n}=\frac{\mu_{0} I_{0}^{2} N}{4 \pi \rho} \boldsymbol{n}
$$

Since the density of electrodynamic forces along the perimeter of each coil increases as it approaches to the vertical axis of the torus, the forces are unbalanced and the resultant force $\boldsymbol{F}_{0 R}=\int_{l} \boldsymbol{f}_{0} d l=F_{0 R} \boldsymbol{e}_{\rho}$ is directed in the radial direction to the vertical axis.

Radial directed forces act to the elements of the support structure, which in this case can be represented as a dense system of a large number of rings located on the generatrix torus (Fig. 2, $a$ ). In this case, all characteristics (ring thickness $h(l)$, Young's modulus of the ring material $E(l)$, stresses $\sigma(l)$ ) will be represented as continuous functions of length along the perimeter of torus cross-section calculated from the starting point.

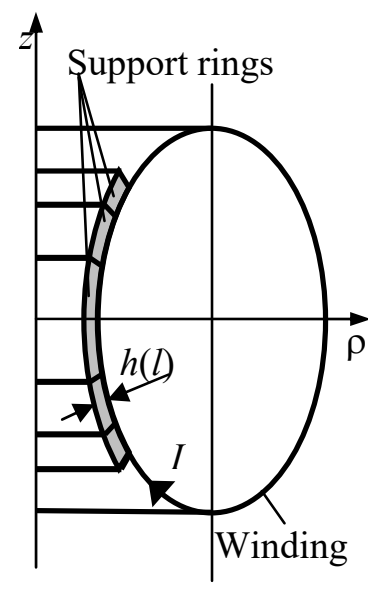

$a$

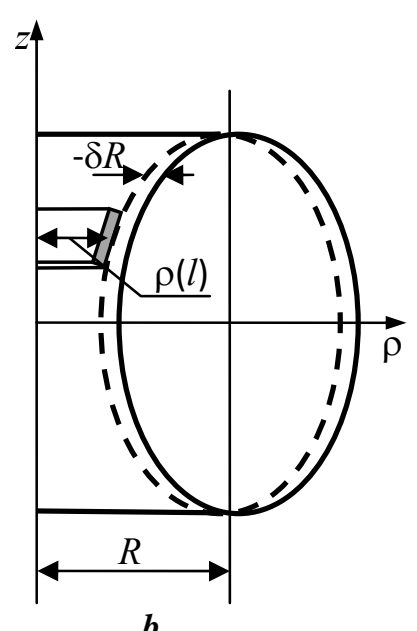

b

Fig. 2

To determine the required volume of the supporting structure, we will use the model of virtual work $\delta A$ of forces with a virtual change of the generalized coordinate, in this case the large radius of the torus $R$, and the associated virtual change of magnetic field energy $\delta W$. All other generalized coordinates that characterize the state of the system are considered constant, i.e. the geometry of the coils (cross-section of the torus) does not change. The projection of radial forces on the radial direction is negative and it leads to compression of the supporting structures. For this reason, in Fig. 2, $b$ the virtual change $-\delta R$ are shown as negative value.

Since the current at elementary movement $\delta R$ remains unchanged, the corresponding relation between the virtual work $\delta A$ of the generalized force and the change in energy $\delta W$ of the system will be 
following [36]:

$$
\delta A=\delta W, \text { where } \delta W=\frac{\partial W}{\partial R} \delta R=F_{R} \delta R .
$$

Here the generalized force is the sum of the radial forces of all coils $F_{R}=F_{0 R} N$.

We present the energy of the field distributed in the volume of the torus in the form of the product of dimensional quantities and dimensionless characteristic $k_{W}\left(\varepsilon_{1}, \varepsilon_{i}\right)$ :

$$
W=\int_{V} \frac{B^{2}}{2 \mu_{0}} d V=\frac{\mu_{0} I^{2} R}{4} k_{W}\left(\varepsilon_{1}, \varepsilon_{i}\right) .
$$

The energy of the field (10) depends on both the large radius $R$ of the torus and the dimensionless parameters $\varepsilon_{1}, \varepsilon_{i}$, where only the first parameter $\varepsilon_{1}$ (the relative radial size of the cross-section of the torus) is also determined by the value of $R$. Hence the generalized radial force can be found as

$$
F_{R}=\frac{\partial W}{\partial R}=\frac{\mu_{0} I^{2}}{4} k_{W}\left(1-\frac{\varepsilon}{k_{W}} \frac{\partial k_{W}}{\partial \varepsilon}\right) .
$$

The radial force $F_{R}$ is distributed between the rings with some linear density $f_{R}(l)$, for which $F_{R}=\int_{L} f_{R}(l) d l$, where $L$ is the length of the generatrix torus with support rings.

Let's obtained one feature, which is that the support requirement does not depend on the radius of the individual rings.

We will assume that each elementary radial force from each coil $f_{R} d l / N$ (Fig. 3, $a$ ) is transmitted by a connecting element with a cross section $d S_{s}$ (Fig. 3, $b$ ) to an elementary support ring of radius $R_{k}$ with a cross-section $d S_{k}$. Each connecting element is under compressive force and there are compressive stresses $\sigma_{s}$. The elementary support ring is also subjected to compressive forces and the stresses $\sigma_{k}$ take place in it. The volumes of structural material of all connecting elements $d V_{s}$ and elementary support ring $d V_{k}$ are

$$
\begin{aligned}
& d V_{s}=N d S_{s}\left[\rho(l)-\rho_{k}\right]=\frac{f_{R}(l) d l}{\sigma_{s}}\left[\rho(l)-\rho_{k}\right], \\
& d V_{k}=2 \pi \rho_{k} d S_{k}=\frac{f_{R}(l) d l}{\sigma_{k}} \rho_{k} .
\end{aligned}
$$

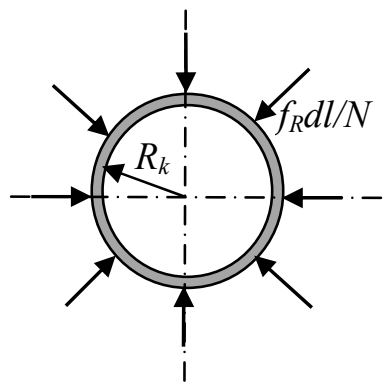

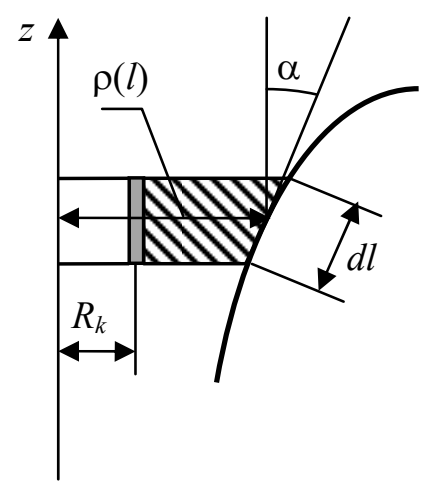

$\boldsymbol{b}$

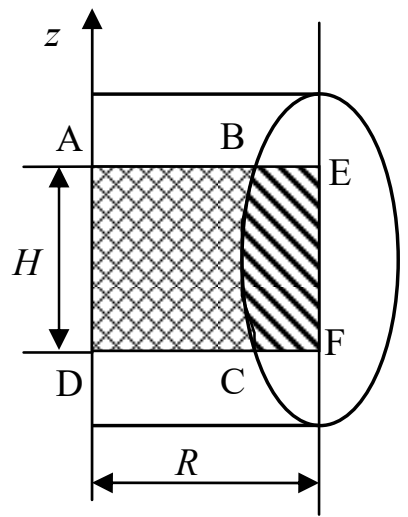

C

Fig. 3 
On condition the same compression stresses $\sigma_{s}=\sigma_{k}=\sigma_{c}$, the total volume of the connecting elements and the elementary support ring are the following:

$$
d V_{s}+d V_{k}=\frac{f_{R}(l) d l}{\sigma_{k}} \rho(l)=d V_{c} .
$$

Thus, on condition $\sigma_{s}=\sigma_{k}=\sigma_{c}$ the required volume of support structure does not depend on the radii of the support rings. It depends only on the radii from which the coils transmit forces to the support rings. For this reason, we will consider the support system when the support rings are located directly on the toroidal surface.

When under the action of radial force the large radius of the torus is changed by the length $\delta R$, each elementary ring is changed by $2 \pi \delta R$ and in the ring there is a compressive force $d T_{c}(l)$. The ring is in compression stress $\sigma_{c}(l)$ and the compressive force appears $d T_{c}(l)=\sigma_{c}(l) d S(l)$, where the cross-section area of the elementary ring is $d S(l)=h(l) d l$. The work of compressive forces of all rings will be the following

$$
\delta A=\int_{L} d T_{c}(l) 2 \pi \delta R=2 \pi \delta R \int_{L} \sigma_{c}(l) h(l) d l=F_{R} \delta R,
$$

or

$$
F_{R}=2 \pi \int_{L} \sigma_{c}(l) h(l) d l .
$$

On the other hand, according to Hooke's law, the stresses in the rings are proportional to their relative deformation (the sign "-" corresponds to the compression stress). Using this law, from (15) we obtain the relation between the generalized force $F_{R}$ and the virtual change of the large radius of the torus $\delta R$ as follows:

$$
\delta R=-\frac{F_{R}}{2 \pi \int_{L} E(l) h(l) / \rho(l) d l} .
$$

Taking into account (16), as well as (10) and (11) we obtain the basic general relation between stress $\sigma_{c}(l)$, Young's modulus $E(l)$ and geometric size (radius of the elementary ring) $\rho(l)$ :

$$
\frac{\sigma(l) \rho(l)}{E(l)}=\frac{F_{R}}{2 \pi \int_{L} E(l) h(l) / \rho(l) d l}=\frac{W}{2 \pi R}\left(1-\frac{\varepsilon}{k_{W}} \frac{\partial k_{W}}{\partial \varepsilon}\right)\left[\int_{L} \frac{E(l) h(l)}{\rho(l)} d l\right]^{-1} .
$$

As can be seen from (17), for chosen support system, the local value $\sigma(l) \rho(l) / E(l)$ does not depend on the coordinate $l$, i.e. each of the parameters is not independent.

Another characteristic is important for the analysis of support systems. It concerns the distribution of radial forces along the generatrix torus $f_{R}(l)$. This distribution is easy to determine if we take into account that the radial force of the elementary ring cross-section is related with the compression force $d T_{c}(l)$ :

$$
f_{R}(l) d l=2 \pi d T_{c}(l)=2 \pi \sigma_{c}(l) h(l) d l=2 \pi \delta R \frac{E(l) h(l)}{\rho(l)} d l .
$$

Taking into account (16) the distribution of radial forces $f_{R}(l)$ will be

$$
f_{R}(l)=\frac{E(l) h(l)}{\rho(l)} F_{R}\left[\int_{L} \frac{E(l) h(l)}{\rho(l)} d l\right]^{-1} .
$$



requirement

The found equations (17) and (19) are the main ones that allow to determine the support structure

\section{Support structure requirement for average stress}

Let us first consider the volume of support structure based on the average value of the compressive stresses $\left.<\sigma_{c}\right\rangle$ used in the virial theorem.

By definition, the average value of compression stresses $\left\langle\sigma_{c}\right\rangle$ in the volume $V_{c}$ of support rings is

$$
<\sigma_{c}>=\frac{\int_{V c} \sigma_{c} d V}{V_{c}}=\frac{\int_{L} \sigma_{c}(l) 2 \pi \rho(l) h(l) d l}{V_{c}} .
$$

From (20) taking into account (17) the volume of the support system will be

$$
V_{c}=\frac{\int_{L} \sigma_{c}(l) 2 \pi \rho(l) h(l) d l}{<\sigma_{c}>}=\frac{F_{R}}{<\sigma_{c}>} \frac{\int_{L} E(l) h(l) d l}{E(l) h(l) / \rho(l) d l} .
$$

Instead of the force $F_{R}$ taking into account (10) and (11) we write the expression containing the energy of the field $W$ as the main characteristic of the energy storage

$$
V_{c}=\frac{W}{<\sigma_{c}>} Q_{c}=\frac{W}{<\sigma_{c}>}\left(1-\frac{\varepsilon}{k_{W}} \frac{\partial k_{W}}{\partial \varepsilon}\right) \psi
$$

where the expression for the parameter $\psi$ is written as

$$
\psi=\int_{L} E(l) h(l) d l /\left[R \int_{L} E(l) h(l) / \rho(l) d l\right] .
$$

As follows from (22) and (23), the first factor in the dimensionless characteristic $Q_{c}$ is determined by the geometry of the torus cross-section of the torus and the relative radial size $\varepsilon$. The second factor $\psi$ depends on the mechanical properties of the material of the support rings, their thickness and location along the generatrix of the torus. It should be noted that in [32], in which the approaches of the virial theorem are applied to magnetic energy storage systems, the value is equal to one. This is a special case, in contrast to (23), when the support system, in particular, has a constant radius equal to the large radius of the torus.

Two typical cases of the support elements location.

The cases under consideration are typical because they provide a clear explanation of the influence of the support system location to the value of the parameter in expression (23).

The first system contains only those support rings that are located at the points of the perimeter of

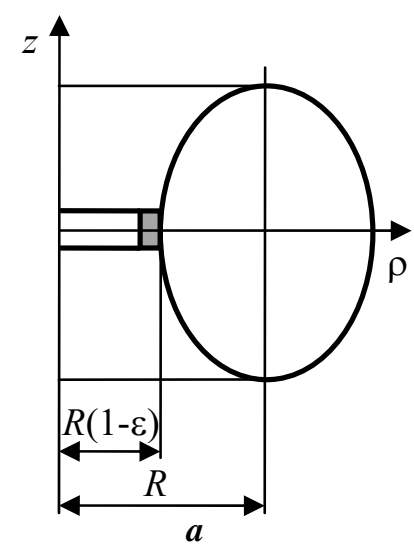

Fig. 4

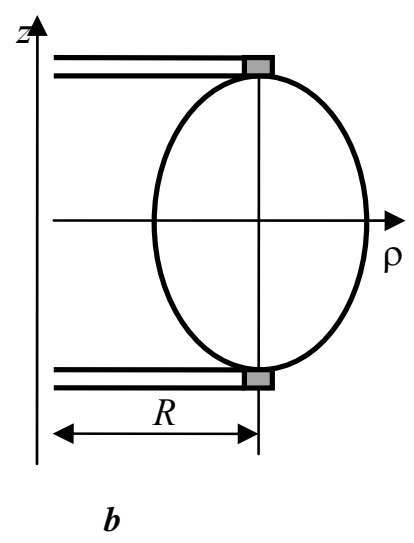

the cross-section of the torus, which are closest to the vertical axis (the radius of support ring has minimum value). As an extreme case of support with small height, it is possible to consider a support system in the form of single ring of the smallest radius (Fig. 4, $a$ ).

In this case, the thickness of the ring can be formally represented in the form $h(l)=h(0) \delta(l)$, where $\delta(l)$ is the $\delta$-Dirac function, and the coordinate $l$ is calculated from the location of the ring. Substituting this value in (23), we obtain the minimum value of the parameter $\psi$ and, accordingly, the minimum value of the modulus of the function $Q_{c}$, and therefore the minimum value 
of the support structure for any selected shape of the torus cross-section:

$$
\psi=\frac{\rho(0)}{R}=1-\varepsilon, Q_{c}=\left(1-\frac{\varepsilon}{k_{W}} \frac{\partial k_{W}}{\partial \varepsilon}\right)(1-\varepsilon) .
$$

If coils (the shape of the torus cross-section) of a circular shape are selected, then taking into account the expression for the parameter $k_{W}(\varepsilon)=2\left(1-\sqrt{1-\varepsilon^{2}}\right)$ [27] the dimensionless characteristic $Q_{c}$ takes the value:

$$
Q_{c}=\left(1-\frac{\varepsilon}{k_{W}} \frac{\partial k_{W}}{\partial \varepsilon}\right)(1-\varepsilon)=-\left(\frac{1}{\sqrt{1-\varepsilon^{2}}}\right)(1-\varepsilon)=-\sqrt{\frac{1-\varepsilon}{1+\varepsilon}}
$$

Another example of the closest to the vertical axis location of the support system is a toroidal system with D-shaped coils (Fig. 5, a) [27, 29]. In this case, also $\psi=1-\varepsilon$. For this system, the forces on the curved section of the coils are balanced, and the forces on the vertical section are uniformly distributed along the height of the support. Therefore, the support system can be performed not in the form of individual rings, but as a solid support cylinder.

At a given value of the current of the D-shaped torus in [29] was found the energy of the magnetic field, whence the expression for the dimensionless characteristic $k_{W}$ can be written as following:

$$
k_{W}=2 k^{2} \sqrt{1-\varepsilon^{2}}\left[I_{0}(k)+\frac{k-1}{k} I_{1}(k)\right],
$$

where $I_{0}(k)$ and $I_{1}(k)$ are modified Bessel functions of the first kind of zero and first order, respectively; $k=\frac{1}{2} \ln \left(\frac{1+\varepsilon}{1-\varepsilon}\right)$. Taking into account (26) from expression (24) we find the expression of the characteristic $Q_{c}$

$$
Q_{c}=\left[k-1+k \frac{I_{0}(k)}{I_{1}(k)}\right]^{-1}
$$

The same result is found in the direct calculation of the support system, based on the value of the magnetic field pressure on the surface of the cylinder of known height.

In the second extreme case (Fig. 4, $b$ ), the two support rings are located at the points of the torus surface for which $\rho\left(l_{0}\right)=R$. Therefore, the corresponding characteristics, as follows from (23), will have the values obtained in [32]:

$$
\psi=\frac{\rho(0)}{R}=1, \quad Q_{c}=\left(1-\frac{\varepsilon}{k_{W}} \frac{\partial k_{W}}{\partial \varepsilon}\right) .
$$

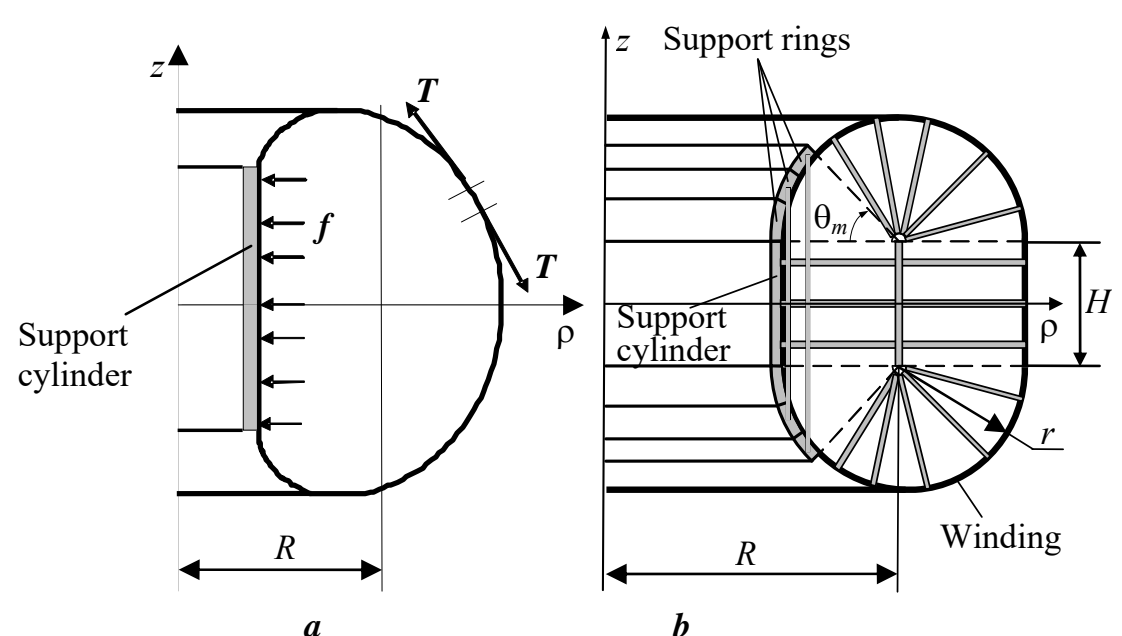

Fig. 5.

At any value of the relative radial size of the torus cross-section $\varepsilon$, the value $\left|Q_{c}\right|$ in (28) is always larger than in (24). In addition, the dependence on the parameter $\varepsilon$ can differ significantly. For example, for torus with circular cross-section equation (25) shows a decrease in magnitude $\left|Q_{c}\right|$ with increase $\varepsilon$. At the same time, at $\psi=1$ from (28) it follows that the value $\left|Q_{c}\right|$ increases with increase $\varepsilon$. 
Let us analyze the value of the parameter $\psi$ for different cases of the support rings location, for the distribution values of the Young's modulus of the rings, and for different distribution of the compressive stresses.

Uniform compressive stress throughout the support system $\sigma_{c}(l)=\sigma_{c}=$ const $\left(\left\langle\sigma_{c}\right\rangle=\sigma_{c}\right)$.

In this case, as it follows from the general relation (17) the Young's modulus $E(l)$ must be chosen different for the individual elements of the support system namely in proportion to the radius of the support rings $\rho(l)$ :

$$
E(l)=2 \pi \rho(l) \frac{1}{F_{R}} \int_{L} E(l) h(l) / \rho(l) d l .
$$

The equation (19) gives the following distribution of radial forces along the perimeter of the torus crosssection within the length $L$ :

$$
f_{R}(l)=F_{R} h(l) / \int_{L} h(l) d l
$$

The multiplier $\psi=\psi_{\sigma}$ in this case of uniform compressive stresses takes on the value:

$$
\psi_{\sigma}=\int_{L} h(l) \rho(l) d l /\left[R \int_{L} h(l) d l\right] .
$$

As can be seen from (31), the parameter $\psi_{\sigma}$ does not depend on the specific thickness of the rings $h(l)$, it depends only on the distribution of the relative value of the thickness (for example, normalized to the maximum value). Note also that if the support rings are located on the side of the vertical axis of the torus, then $\rho(l) / R<1$ and consequently $\psi_{\sigma}<1$. If the rings are located on the opposite side, where $\rho(l)>R$, then $\psi_{\sigma}>1$. Obviously, the arrangement of the rings on both sides of the cross-section of the torus can give the value of the parameter $\psi_{\sigma}=1$.

A special case is the uniform distribution of radial forces along the vertical axis $z$, which is realized if the thickness of the rings is distributed according to the law $h(l) \sim \cos \alpha$, where $\alpha$ is the angle between the vertical axis and tangent to the generatrix torus (Fig. 3, b). In this case, as it follows from (30), $f_{R}=F_{R} / H$, where $H=\int_{L} \cos \alpha d l=\int_{z} d z$ is the vertical size of the support system. This distribution is important because in the design of the support system, the coils often have a support in the form of a straight cylinder, in which there are no bending mechanical moments and there are only compressive stresses. The value of the factor $\psi_{\sigma}$ at $\sigma_{c}(l)=$ const and $h(l) \sim \cos \alpha$ has a simple geometric interpretation. This factor is equal to the ratio of the planes, as shown in Fig. 3, $c, \psi_{\sigma}=S_{A B C D} / S_{A E F D}$.

An example of the support structure under condition $\sigma_{c}=$ const, $h(l) \sim \cos \alpha$ is toroidal magnets with racetrack shaped coils (Fig. 5, b). Determination of the characteristics of such system, in particular, the structure requirement, was performed in [37] using direct calculation of electrodynamic forces. The feature of this toroidal storage design is that the elements of the support system under tensile forces are inside the toroidal volume. To implement this configuration, the curved sections outside the section with the support rings are balanced by choice of angle $\theta_{m}$. As a result, the support elements meet action only forces from the sections of the winding that support on the rings. The expression obtained in [37] for the characteristic $Q_{c}$ is

$$
Q_{c}=\frac{2 \varepsilon^{2}(\lambda-1)+\varepsilon(1+\varepsilon) \sin \theta_{m}}{(1+\varepsilon)\left(\pi\left(1-\sqrt{1-\varepsilon^{2}}\right)+\varepsilon(\lambda-1) \ln \frac{1+\varepsilon}{1-\varepsilon}\right)},
$$

where $\lambda=H / 2 r=\left(H_{c}+2 r\right) / 2 r$. Expression (32) is also in accordance with the results derived from the presented theoretical positions. It should be taken into account that for a balanced section the angle $\theta_{m}$ depending on $\varepsilon$ is determined by the solution of the nonlinear algebraic equation: 


$$
\pi-\theta_{m}-\frac{2}{\sqrt{1-\varepsilon^{2}}} \operatorname{arctg}\left(\sqrt{\frac{1-\varepsilon}{1+\varepsilon}} \operatorname{ctg} \frac{\theta_{m}}{2}\right)=0
$$

We give more the results for a special case of system with circular coils of radius $r$ (Fig. 6) and support system symmetrical about the horizontal plane at arbitrary value of the angle $\theta_{m}$.

In this case, the general expression for the multiplier $\psi_{\sigma}$ looks like this:

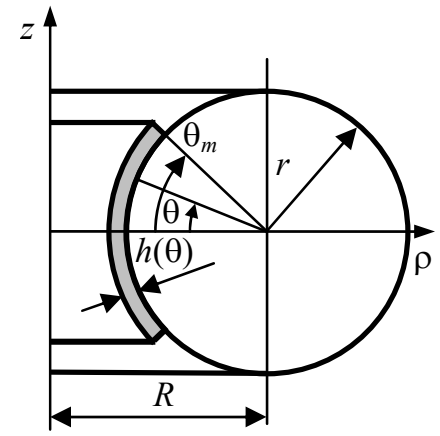

Fig. 6.

$$
\psi_{\sigma}=\int_{0}^{\theta_{m}} h(\theta)(1-\varepsilon \cos \theta) d \theta / \int_{0}^{\theta_{m}} h(\theta) d \theta .
$$

The value $\psi_{\sigma}$ for the two characteristic distributions of the support rings thickness $h(\theta)$ will be as follows:

1) $h(\theta)=$ const - uniform thickness of the rings along the perimeter of the torus cross-section

$$
\psi_{\sigma}=1-\varepsilon \frac{\sin \theta_{m}}{\theta_{m}} ;
$$

2) $h(\theta) \sim \cos \theta$ - uniform distribution of electrodynamic forces along the axis $z$

$$
\psi_{\sigma}=1-\frac{\varepsilon}{\sin \theta_{m}}\left(\frac{\theta_{m}}{2}+\frac{1}{4} \sin 2 \theta_{m}\right)
$$

Support structure with the same value of the Young's modulus $E(l)=$ const for all rings

In the case $E(l)=$ const from the general relation (17) it follows that the stresses are non-uniformly distributed along the generatrix of torus and they has the maximum value $\sigma_{c}(l)$ for the rings of the smallest radius $\rho(l)$ :

$$
\sigma_{c}(l)=\frac{F_{R}}{2 \pi \rho(l) \int_{L} h(l) / \rho(l) d l} .
$$

The distribution of the radial forces along coordinate $l$, as it follows from (19), is

$$
f_{R}(l)=F_{R} \frac{h(l)}{\rho(l)}\left[\int_{L} h(l) / \rho(l) d l\right]^{-1} .
$$

From (23) we receive the value of the parameter $\psi=\psi_{E}$ that is valid for the average value of compressive stresses and for $E(l)=$ const :

$$
\psi_{E}=\int_{L} h(l) d l /\left[R \int_{L} h(l) / \rho(l) d l\right] .
$$

As before, we present the results for a torus with circular cross-section. The multiplier $\psi_{E}$, which depends on the thickness of the rings $h(\theta)$, for a support system symmetrical with respect to the horizontal plane, will be:

$$
\psi_{E}=\int_{0}^{\theta_{m}} h(\theta) d \theta / \int_{0}^{\theta_{m}} h(\theta) /(1-\varepsilon \cos \theta) d \theta
$$

The values $\psi_{E}$ for the two typical thickness distribution $h(\theta)$ will be as follows: 
1) $h(\theta)=$ const :

$\psi_{E}=\theta_{m} \sqrt{1-\varepsilon^{2}}\left[2 \operatorname{arctg}\left(\sqrt{\frac{1+\varepsilon}{1-\varepsilon}} \operatorname{tg} \frac{\theta_{m}}{2}\right)\right]^{-1} ;$

2) $h(\theta) \sim \cos \theta:$

$$
\psi_{E}=\varepsilon \sin \theta_{m}\left[-\theta_{m}+\frac{2}{\sqrt{1-\varepsilon^{2}}} \operatorname{arctg}\left(\sqrt{\frac{1+\varepsilon}{1-\varepsilon}} \operatorname{tg} \frac{\theta_{m}}{2}\right)\right]^{-1} .
$$

The presented examples differ in the distribution of the compressive stresses, mechanical properties of the structural material, as well as specific distributions of the support rings thickness. It is advisable to compare them in terms of the structure requirement at given storage energy, comparing the dimensionless characteristics $Q_{c}$. For circular coils the corresponding dependences of the characteristics $Q_{c}$ on the angle $\theta_{m}$ that determines the size of the areas where the support rings are located are shown in Fig. 7, $a$ and $b$ for two values of the relative radial size of the torus: $(a)-\varepsilon=0,3$ and $(b)-\varepsilon=0,6$. Solid curves refer to the case $E(l)=$ const , dashed lines correspond $\sigma_{c}=$ const .

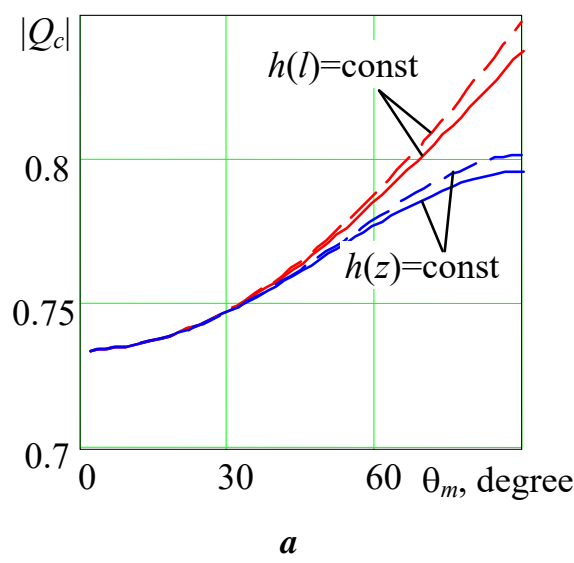

Fig. 7

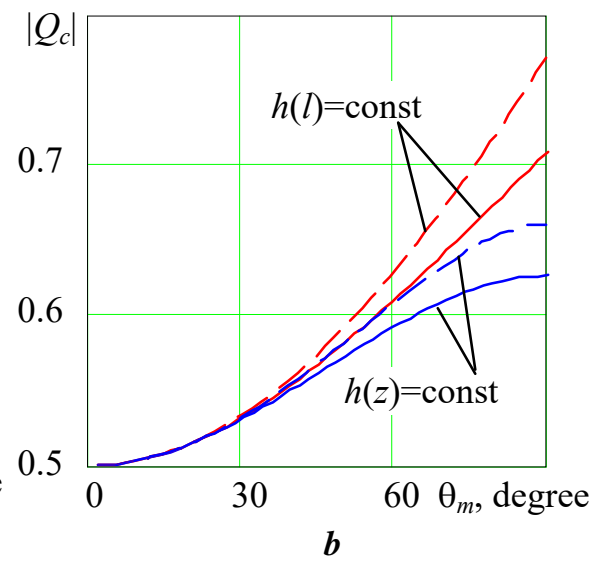

$\boldsymbol{b}$

As can be seen from Fig. 7, for tori with a larger relative radial cross-sectional size the structure volume is smaller. The distribution of the rings thickness under the condition $\quad h(l) \sim \cos \theta \quad$ i.e. $h(z)=$ const leads to smaller structure volume compared to the uniform thickness of the support rings.

A smaller amount of material will be in the case of choosing the same material properties for all rings $E(l)=$ const, and it would seem that such choice is more appropriate. Note, however, that the conclusion relates to the values found for the average stresses $\left\langle\sigma_{c}\right\rangle$, and not taking into account the choice of material for the most mechanically stressed element of the support structure.

\section{Support structure requirement by the condition of maximum stresses}

In the case of $E(l)=$ const the greatest stress $\sigma_{c \max }$ will be in the ring of the smallest radius $\rho_{\min }$. That is, the stress in this ring determines the choice of mechanical property of the support structure. We find the expressions for the characteristics of the support system in this case and analyze them.

The problem is to determine the volume of the support structure $V_{c \max }=\int_{L} 2 \pi h(l) \rho(l) d l$, taking into account the expression $\sigma_{c}(l) \rho(l)=\sigma_{c \max } \rho_{\min }=$ const that follows from the general equation (17) at $E(l)=$ const. To do this, in the integrand for the volume $V_{c \max }$, we perform the substitution $2 \pi h(l)=f_{R}(l) / \sigma_{c}(l)$ that follows from (18):

$$
V_{c \max }=\int_{L} \frac{f_{R}(l) \rho^{2}(l)}{\sigma_{c}(l) \rho(l)} d l=\frac{1}{\sigma_{c \max } \rho_{\min }} \int_{L} f_{R}(l) \rho^{2}(l) d l .
$$

Taking into account (19) and (21) from (43) we obtain:

$$
V_{c \max }=\frac{F_{R}}{\sigma_{c \max } \rho_{\min }} \int_{L} h(l) \rho(l) d l / \int_{L} h(l) / \rho(l) d l=\frac{W}{\sigma_{c \max }} Q_{c \max },
$$


where

$$
Q_{c \max }=\left(1-\frac{\varepsilon}{k_{W}} \frac{\partial k_{W}}{\partial \varepsilon}\right) \psi_{E \max }, \quad \psi_{E \max }=\int_{L} h(l) \rho(l) d l /\left[R \rho_{\min } \int_{L} h(l) / \rho(l) d l\right] .
$$

The results are illustrated by an example of the circular cross-section torus (Fig. 6), for which the parameter $\psi_{E \text { max }}$ takes the form:

$$
\psi_{E \max }=\int_{0}^{\theta_{m}}(1-\varepsilon \cos \theta) h(\theta) d \theta /\left[\left(\rho_{\min } / R\right) \int_{0}^{\theta_{m}} h(\theta) /(1-\varepsilon \cos \theta) d \theta\right] .
$$

Again, consider the following two cases:

1) $h(\theta)=$ const : $\quad \psi_{E \max }=\left(\theta_{m}-\varepsilon \sin \theta_{m}\right)\left[2 \sqrt{\frac{1-\varepsilon}{1+\varepsilon}} \operatorname{arctg}\left(\sqrt{\frac{1+\varepsilon}{1-\varepsilon}} \operatorname{tg} \frac{\theta_{m}}{2}\right)\right]^{-1}$;

2) $h(\theta) \sim \cos \theta: \quad \psi_{E \max }=\varepsilon\left[\sin \theta_{m}-\varepsilon\left(\frac{\theta_{m}}{2}+\frac{1}{4} \sin 2 \theta_{m}\right)\right]\left[-(1-\varepsilon) \theta_{m}+2 \sqrt{\frac{1-\varepsilon}{1+\varepsilon}} \operatorname{arctg}\left(\sqrt{\frac{1+\varepsilon}{1-\varepsilon}} \operatorname{tg} \frac{\theta_{m}}{2}\right)\right]^{-1}$.

We will compare the dimensionless characteristics $Q_{c}$, when choosing $\sigma_{c}=$ const, $E(l)=$ var and $\sigma_{c}=\sigma_{c \max }, E(l)=$ const (Fig. 8). As before, the results are given for two values of the relative radial size of the torus: $(a)-\varepsilon=0.3$ and $(b)-\varepsilon=0.6$. Solid curves refer to the case $\sigma_{c}=\sigma_{c \max }, E(l)=$ const, dashed lines correspond $\sigma_{c}=$ const, $E(l)=$ var .

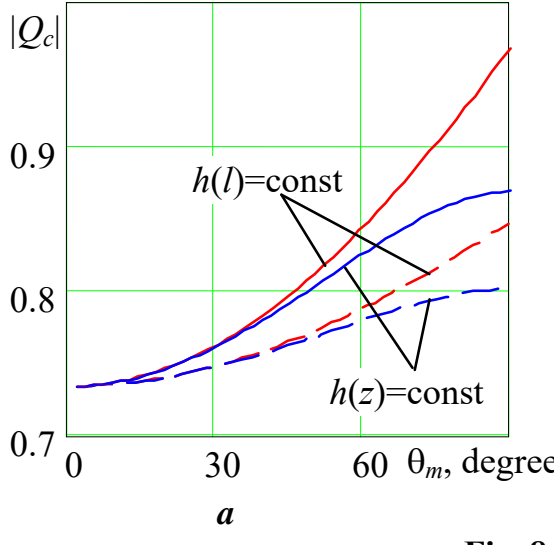

Fig. 8

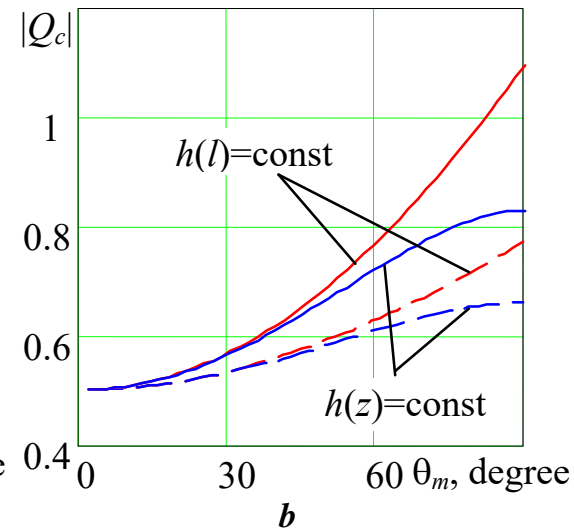

(1)

of fulfilling the conditions $\sigma_{c}=$ const in practice, it is still more likely to choose the material by condition $\sigma_{c \max }$. As follows from the presented results, it is more appropriate to distribute the cross-section of the support rings, when uniform distribution of compressive forces along the vertical axis occurs, i.e. $h(z)=$ const $\rightarrow h(\theta) \sim \cos \theta$.

\section{The total structure requirement of toroidal energy storage}

The total structural volume is the sum of the two main components. One of them is the volume of the support structure that receives electrodynamic compressive radial directed forces of the torus. Another component is structures that are subjected to tensile stresses (belt around the coils or spokes inside the toroidal volume). A direct calculation of this component for a number of toroidal systems shows that relation (6) $Q_{t}=-Q_{c}+1$ is valid for it. This relation is performed for tori with non-circular D-shaped coils and for tori with racetrack shaped coils (including circular coils) with spokes [37]. In both cases there is a distribution of the thickness of the support rings (cylinder) by condition $\sigma_{c}=$ const, $h(z)=$ const. That is, 
relation (6) occurs not only in the special case of the support structure location, when $\psi=1$. It is valid for support structure when $\psi \neq 1$.

It should be noted that for structures with belts around the coils, the condition of constant tensile stresses is fulfilled not only for the system with D-shaped coils, which are characterized by constant tension along the perimeter of torus cross-section. For other configurations with variable tension, the belts can be made of variable cross-section, for which $\sigma_{t}=$ const and accordingly the volume of the belts material will also be minimal. Otherwise, the volume increases and inequality $Q_{t} \geq\left|Q_{c}\right|+1$ occurs.

We perform a comparison of different support structures on the basis of the general characteristic $Q=\left|Q_{t}\right|+\left|Q_{c}\right|$ for which condition (6) is valid. The Table shows the results of the calculation of the characteristic $Q$ for a number of systems on condition $\sigma_{c}=$ const, $\sigma_{t}=$ const for different values of the relative radial size of the torus cross-section $\varepsilon$.

\begin{tabular}{|c|c|c|c|c|}
\hline$\varepsilon$ & $\begin{array}{l}\text { Circular } \\
\text { coils with } \\
\text { belts }\end{array}$ & $\begin{array}{l}\text { Circular } \\
\text { coils with } \\
\text { spokes }\end{array}$ & $\begin{array}{l}\text { D-shape } \\
\text { coils with } \\
\text { belts }\end{array}$ & $\begin{array}{l}\text { Racetrack } \\
\text { shaped with } \\
\text { spokes }\end{array}$ \\
\hline & & \\
\hline 0.2 & 3.041 & 2.638 & 2.649 & 2.641 \\
\hline 0.4 & 3.182 & 2.338 & 2.362 & 2.344 \\
\hline 0.6 & 3.5 & 2.079 & 2.104 & 2.081 \\
\hline 0.8 & 4.333 & 1.836 & 1.838 & 1.821 \\
\hline
\end{tabular}

As can be seen from the presented data, the distribution method of the support system location has the greatest influence on the total structural volumes. Structure with support elements on side of vertical axis require significantly less volume of support structure. The values for such support systems differ little. Moreover, the influence is appeared in a significantly different dependence of the value $Q$ on the relative radial size of the torus cross-section $\varepsilon$. For structure with support elements on side of the vertical axis of the torus with increasing $\varepsilon$ the value $Q$ decreases, in contrast to the

case where the support elements has the size of large radius of the torus.

Conclusion. The generalization performed on the basis of the virial theorem with respect to any structure in compression for toroidal magnetic energy storage allows us to find specific expressions that, in contrast to existing one, take into account not only the configuration of windings but also the feature of support structure, the distribution of the cross-section areas of the support rings and the corresponding distribution of radial electrodynamic forces, and mechanical properties support elements too.

The expression for the dimensionless characteristics of the components in compression and in tension included in the expressions of the virtual theorem for toroidal magnetic energy storage is valid not only in the case of equality of the radius of the support structure and the large radius of the torus, but in the more general case of arbitrary distribution of the radial forces along the perimeter of torus cross-section.

On condition of identical compressive stresses in the support ring and in the connecting element the required volume of support structure does not depend on the radii of the support rings, it depends only on the radii from which the coils transmit forces to the support rings. Structures with support elements on side of vertical axis of torus require significantly smaller structural volume compare to the case where the support elements has the size of large radius of the torus. The uniform height distribution of radial forces leads to smaller support structure volume compared to the uniform thickness of the support rings.

Further theoretical studies for a wider range of support structure with elements in tension stress will be able to answer the validity of the relation of the virtual theorem for dimensionless characteristics of toroidal magnetic systems. This will make it possible to reasonably indicate the minimum structure requirement, which can be approached in the development of toroidal magnetic energy storage.

Роботу виконано за бюджетною темою «Розробити засоби підвищення ефективності систем електромеханічного перетворення енергії традиційними та відновлюваними джерелами» («Агрегат-2»), КПКВК 6541030. 
1. ITER Physics Basis. Nuclear Fusion. 1999. Vol. 39. No 12.

2. Duchateau J.L., Journeaux J.Y., Gravil B. Tore Supra Superconducting Toroidal Magnetic Field System. Fusion Science and Technology. 2009. Vol. 56. No 3. Pp. 1092-1123. DOI: https://doi.org/10.13182/FST09-A9170

3. Menard J.E., Bromberg L., Brown T. et al. Prospects for pilot plants based on the tokamak, spherical tokamak and stellarator. Nuclear Fusion, Vol. 51. No 10. 103014. DOI: https://doi.org/10.1088/0029-5515/51/10/103014

4. Ribeiro P.F.; Johnson B.K.; Crow M.L.; Arsoy A.; Liu Y. Energy storage systems for advanced power applications. Proceeding IEEE. 2001. Vol. 89. Pp. 1744-1756. DOI: https://doi.org/10.1109/5.975900.

5. Mohamad F., Teh J., Lai C-M., Chen L-R. Development of Energy Storage Systems for Power Network Reliability: A Review. Energies. 2018. Vol. 11. 2278. DOI: https://doi.org/10.3390/en11092278.

6. Devotta J.B.X., Rabbani M.G. Application of superconducting magnetic energy storage unit in multi-machine power systems. Energy Conversion \& Management. 2000. Vol. 41. Pp. 493-504. DOI: https://doi.org/10.1016/S01968904(99)00100-4.

7. Said S.M., Aly M., Abdel-Akher M. Application of Superconducting Magnetic Energy Storage (SMES) for Voltage Sag/Swell Supression in Distribution System with Wind Power Penetration. IEEE 16th International Conference on Harmonics and Quality of Power (ICHQP). Bucharest, Romania, May 25-28, 2014. DOI: https://doi.org/10.1109/ICHQP.2014.6842877

8. Borgard L. Voltage stabilization in network used energy storage. Transm.\&Distr.World. 1999. No 9. Pp. $203-208$.

9. Duangkamol K., Mitani Y., Ise T. Tsuji K. Experimental study on power system stabilizing control scheme for the SMES with solid-state phase shifter (Super SMES), IEEE Trans. an Applied Superconductivity. 1999. Vol. 9. No 2. Pp. 326-329. DOI: https://doi.org/10.1109/77.783301

10. Zhou X., Chen X.Y., Jin J.X. Development of SMES Technology and Its Applications in Power Grid. IEEE International Conference on Applied Superconductivity and Electromagnetic Devices. Sydney, Australia, December 14-16, 2011. Pp. 260-269. DOI: https://doi.org/10.1109/ASEMD.2011.6145115

11. Avramenko V.M., Aristov Yu.V., Vasetsky Yu.M., Mazurenko I.L., Cherenenko P.O. Some areas of efficient use of superconducting magnetic energy storage (SMES) in the power systems of Ukraine. Tekhnichna elektrodynamika. Special issue. Problems of present-day elektrotechnics. Part. 3. 2008. Pp. 43-48. (Ukr)

12. Yakimets I.V., Dmitrieva G.A. Directional regulation of the active power of a superconducting magnetic energy storage. Elektrichestvo. 2001. No 8. Pp. 1-9. (Rus)

13. Boeing H.J., Hauer J.F. Commissioning tests of the Bonneville power administration 30 MJ Superconducting magnetic energy storage unit. IEEE Trans. Power Apparatus Systems. 1985. Vol. 104. Issue 2. Pp. 302-312. DOI: https://doi.org/10.1109/TPAS.1985.319044

14. Ali M. H., Wu B., Dougal R. A. An Overview of SMES Applications in Power and Energy Systems. IEEE Transactions on Sustainable Energy. 2010. Vol. 1. No 1. Pp. 38-47. DOI: https://doi.org/10.1109/TSTE.2010.2044901

15. Vasetsky Yu.M., Mazurenko I. L, Pavlyuk A. V. Compensation of nonregular oscillations of the active power overflows through the transmission line with the help of superconducting magnetic energy storage. Elektrichestvo. 2014. No 2. Pp. 10-17. eLIBRARY ID: 21094673. ( Rus).

16. Nomura S., Shintomi T., Akita Fellow S., Tanzo Nitta T., Shimada R., Meguro S. Technical and Cost Evaluation on SMES for Electric Power Compensation. IEEE Trans. Applied Superconductivity. 2010. No 20. Pp. 1373-1378. DOI: https://doi.org/10.1109/TASC.2009.2039745

17. Hamajima T., Tsuda M., Miyagi D. et al. Advanced superconducting power conditioning system with SMES for effective use of renewable energy. Physics Procedia. 2012. Vol. 27. Pp. 396 - $399 . \quad$ DOI: https://doi.org/10.1016/j.phpro.2012.03.494

18. Jin J.X, Chen X.Y. Study on the SMES Application Solutions for Smart Grid. Physics Procedia. 2012. Vol. 36. Pp. 902 - 907. DOI: https://doi.org/10.1016/j.phpro.2012.06.227

19. Brechna H. Superconducting magnet systems. Berlin, New York: Springer, 1973. 590 p.

20. Vasetsky Yu. Asymptotic methods for solving electrodynamics problems in systems with bulky curvilinear conductors. Kyiv: Naukova dumka, 2010. 271 p. (Rus)

21. Volkov E.D., Suprunenko V.A., Shishkin A.A. Stellarator. Kiev: Naukova dumka, 1983. 312 p. (Rus)

22. Matsukawa T., Nakamura H., Nomura S., Sato Y., Tsuji-Iio S., Shimada R.. Conceptual Design of SMES System Equipped for IPP Plant. IEEE Transactions on Applied Superconductivity. 2000. Vol. 10. No 1. Pp. 788-791. DOI: https://doi.org/10.1109/77.828349

23. Nomura S., Chikaraichi H., Tsutsui H., Shimada R. Feasibility Study on Large Scale SMES for Daily Load Leveling Using Force-Balanced Helical Coils. IEEE Transactions on Applied Superconductivity. 2013. Vol. 23. Issue 3. 5700904. DOI: https://doi.org/10.1109/TASC.2012.2237494

24. Fabbri M., Ajiki D., Negrini F., Shimada R., Tsutsui H., Venturi F. Tilted toroidal coils for superconducting magnetic energy storage systems. IEEE Transactions on Magnetics. 2003. Vol. 39. Issue 6. Pp. 3546 - 3550. DOI: https://doi.org/10.1109/TMAG.2003.819483 
25. Vasetsky Yu., Georgiyevskiy A., Ostrow S., Rotachov Yu. Toroidal magnetic systems with tilted coils for superconducting magnetic energy storage (SMES). Tekhnichna elektrodynamika. Special issue. Problems of presentday elektrotechnics. Part. 2. 2004. Pp. 3-6. (Ukr).

26. Vasetsky Yu., Mazurenko I., Aristov Yu. Thin Toroidal Superconducting Magnetic Energy Storage (SMES) with Tilted Coils: Dimension and Mass Parameters, Stray Magnetic Fields. Przeglad Elektrotechniczny (Electrical Review). 2009. No 4. Pp. 95-97. URL: http://pe.org.pl/issue.php?lang=1\&num=04/2009

27. Thome R.J., Tarrh J.M. MHD and Fusion Magnets. Field and Force Design Concepts. New York: A WileyInterscience Publication, 1982. 316 p.

28. Leytes L.V. Coreless toroidal reactor for power systems. Elektrichestvo. 1960. No 11. Pp. 76-81. (Rus)

29. Larionov B.A., Spevakova F.M., Stolov A.M., Azizov E.A. Problems of accumulation and conversion of electromagnetic energy in pulse power systems with magnetic energy storage. Physics and technique of powerful impulse systems. Moskva: Energoatomizdat, 1987. Pp. 66-104. (Rus)

30. Georgiyevskiy A. Ostrow S., Vasetsky Y. Superconducting Magnetic Energy Storage (SMES) Systems with Spoke Support Structure Placed Inside a Torus. Proceedings of the VII Intern. Workshop: Computation Problems of Electrical Engineering. Jazleevets, 2003. Pp. 24-27.

31. Mazurenko I., Pavlyuk A., Vasetsky Y. Parameters of superconducting magnets with racetrack-shaped coils and support structure placed inside torus. Przeglad Elektrotechniczny (Electrical Review). 2012. Vol. 88. No 3a. Pp. 67-69. URL: http://pe.org.pl/articles/2012/3a/23.pdf

32. Eyssa Y., Boom R. Considerations of a large force balanced magnetic energy storage system. IEEE Transactions on Magnetics. 1981. Vol. 17. Issue 1. Pp. 460-462. DOI: https://doi.org/ 10.1109/TMAG.1981.1061108

33. Levy R.H. Author's Reply to Willinski's Comment on Radiation Shielding of Space Vehicles by Means of Superconducting Coils. AVCO Research Laboratory Journal. June, 1962.

34. Moon F.C. The virial theorem and scaling laws for superconducting magnet systems. Journal of Applied Physics. 1982. Vol. 53. Issue 12. Pp. 9112-9121. DOI: https://doi.org/10.1063/1.330423

35. Nomura S., Tsutsui H. Structural Limitations of Energy Storage Systems Based on the Virial Theorem. IEEE Transactions on Applied Superconductivity. 2017. Vol. 27. Issue 4. 5700106. DOI: https://doi.org/10.1109/TASC.2017.2652858.

36. Polivanov K.M. Theoretical bases of electrical engineers. Vol. 3. Theory of Electromagnetic Field. MoskvaLeningrad: Energiia, 1965. 352 p. (Rus)

37. Vasetsky Y.M. Mazurenko I.L, Pavlyuk A.V. Comparison of superconducting magnets with mechanical support elements placed inside torus. Tekhnichna electrodynamika. 2013. No 4. Pp. 13-21.

\title{
ОБМЕЖЕННЯ ТЕОРЕМИ ВІРІАЛУ ДЛЯ ТОРОЇДАЛЬНОГО ІНДУКТИВНОГО НАКОПИЧУВАЧА, ЩО ОБУМОВЛЕНІ РОЗТАШУВАННЯМ ЕЛЕМЕНТІВ ОПОРНОЇ КОНСТРУКЦІЇ ТА ЇХНІМИ МЕХАНІЧНИМИ ВЛАСТИВОСТЯМИ
}

\author{
Ю.М. Васецький, докт. техн. наук \\ Інститут електродинаміки НАН України, \\ пр. Перемоги, 56, Київ, 03057, Україна. \\ E-mail: yuriy.vasetsky@gmail.com
}

На основі теореми віріала розглядається вплив на характеристики механічних опорних систем тороїдальних індуктивних накопичувачів енергї наступних факторів: конфігурачї котушок тороїдального магнітного поля, розташування елементів опорної системи, щяо сприймають зусилля стиску, механічних властивостей конструкційного матеріалу, розподілу площ перерізу опорних кілещьь $i$ відповідний розподіл радіальних електродинамічних сил. Встановлено, щчо об'єм конструкиійного матеріалу залежить тільки від тих радіусів, з яких котушки передають зусилля на опорні кільия. Знайдено загальне співвідношення, яке, на відміну від існуючих, встановлюе зв'язок між всіма параметрами, щзо впливають на об'єм матеріалу опорних конструкиій. Проаналізовано характеристики опорних систем для випадків однакових механічних напруг та однакових механічних властивостей матеріалу конструкиій. Знайдено характеристики для конкретних прикладів тороїдальних систем з круглими котушками. Показано, щяо системи з опорними елементами, розташованими на тороїдальній поверхні зі сторони вертикальної осі тора, мають значно менший об'єм конструкиійного матеріалу порівняно з іншим розташуванням. Досліджено вплив на об'єм матеріалу відносного радіального розміру перетину тору та розподілу площ перетину опорних кілець вздовж периметру котушок. Відзначено зв'язок між безрозмірними характеристиками, щуо визначають кількість матеріалу елементів, щз зазнають механічні напруги стиску і розтягнення. Бібл. 37, рис. 8, табл. 1.

Key words: тороїдальні індуктивні накопичувачі енергії, теорема віріала, стискання опорних елементів, об’ $€$ м опорних конструкцій. 